\title{
MCDA4ArcMap: An Open-Source Multi-Criteria Decision Analysis and Geovisualization Tool for ArcGIS 10
}

\author{
Claus Rinner \\ Ryerson University
}

\section{Steffan Voss}

University of Münster

Rinner, C., \& Voss, S. (2013). MCDA4ArcMap: An open-source multi-criteria decision analysis and geovisualization tool for ArcGIS 10. Cartouche, 86, 12-13.

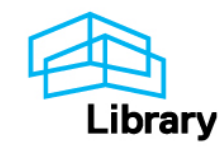




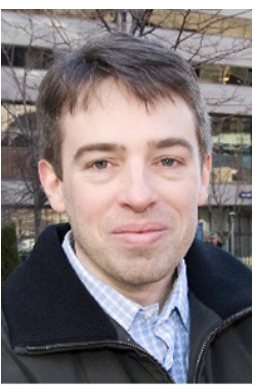

Claus Rinner

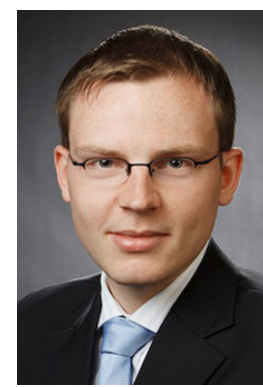

Steffan Voss

\section{MCDA4ArcMap - An Open-Source Multi-Criteria Decision Analysis and Geovisualization Tool for ArcGIS 10}

weights should depend on the ranges of criterion values occurring in a specific decision problem.

our decision-making on a rational framework, which often includes multiple decision criteria. Spatial decision problems have been characterized as a set of geographically defined decision alternatives (locations) with associated criterion values (e.g., Malczewski 1999). Within Geographic Information Systems (GIS), multi-criteria decision analyses (MCDA) tools have been used for decision support in environmental, transportation, and urban/regional planning, in waste management, as well as in hydrology, agriculture, and forestry, to name but a few areas of application (Malczewski 2006). Often, MCDA tools are only loosely coupled with GIS software (e.g., calculations completed in a spreadsheet) or take the form of custom implementations in a GIS scripting/programming environment. Few GIS vendors have integrated generic MCDA functionality in their products, with the notable exceptions of Idrisi's Multi-Criteria Evaluation module and ArcGIS' Overlay Toolset. Both of these operate on raster data layers using map algebra operations to combine cell values into an evaluation score for each candidate location (raster cell).

In this technical note, we present "MCDA4ArcMap", an opensource tool for MCDA and geovisualization of vector data in ArcMap. The analytical functionality of the tool includes three MCDA methods: weighted linear combination (WLC), ordered weighted averaging (OWA), and a local variant of WLC (LWLC). WLC corresponds to the weighted overlay tool that readers may know from ArcGIS. As an extension of the criterion importance weighting in WLC, the OWA method allows the decision-maker to specify a degree of risk in their approach to decision-making. OWA has been implemented previously in Idrisi (liang \& Eastman 2000). The recently proposed LWLC (Malczewski 20I I) adjusts criterion importance weights with regards to the local range of criterion values. Criterion weights are increased in a neighbourhood, if their local range is large relative to their global range in the study area, or decreased if the local range is relatively small. This approach adheres to the range-sensitivity principle that stipulates that criterion
Given the many parameters that influence MCDA outcomes, previous research has argued for using interactive graphical tools, including thematic maps, to explore the impact of input parameter settings on MCDA results. Jankowski et al. (200I) integrated cutting-edge interactive thematic mapping in CommonGIS (then called "Descartes") with MCDA and data mining techniques. They recommended a map-centred exploratory approach to MCDA that uses maps as "visual thinking" tools according to the modern cartography literature (DiBiase 1990, MacEachren \& Kraak 1997). Subsequently, Rinner \& Taranu (2006, p.647) noted that "an interactive mapping tool is worth a thousand numbers" referring to the use of "multiple cartographic representations for changing decision-making preferences". Further, with reference to the thennew field of visual analytics, Rinner (2007) suggested that geovisualization should not be limited to exploring massive datasets but be applied to the possibly massive output of analytical processes that results from varying input parameters.

Along these lines of research, the MCDA4ArcMap tool combines advanced MCDA methods with interactive thematic maps. Of the two mapping techniques implemented so far, the unclassed choropleth map is the more exciting. It may be known to readers from the CommonGIS software (e.g., Andrienko et al. 2002) but is rather uncommon in commercial GIS. As seen in the screenshot, this implementation allows the user to specify two colours for the minimum and maximum end of the value range of an attribute (here the MCDA score resulting from the analyst's current parameter settings) as well as a neutral colour and a breakpoint for the diverging colour scheme. With reference to discussion and experimentation by academic cartographers in the 1970s and 1980s, Slocum et al. (2009) note that the unclassed choropleth map accurately portrays numerical data relationships, yet is suitable for the acquisition of general information on spatial patterns (rather than 


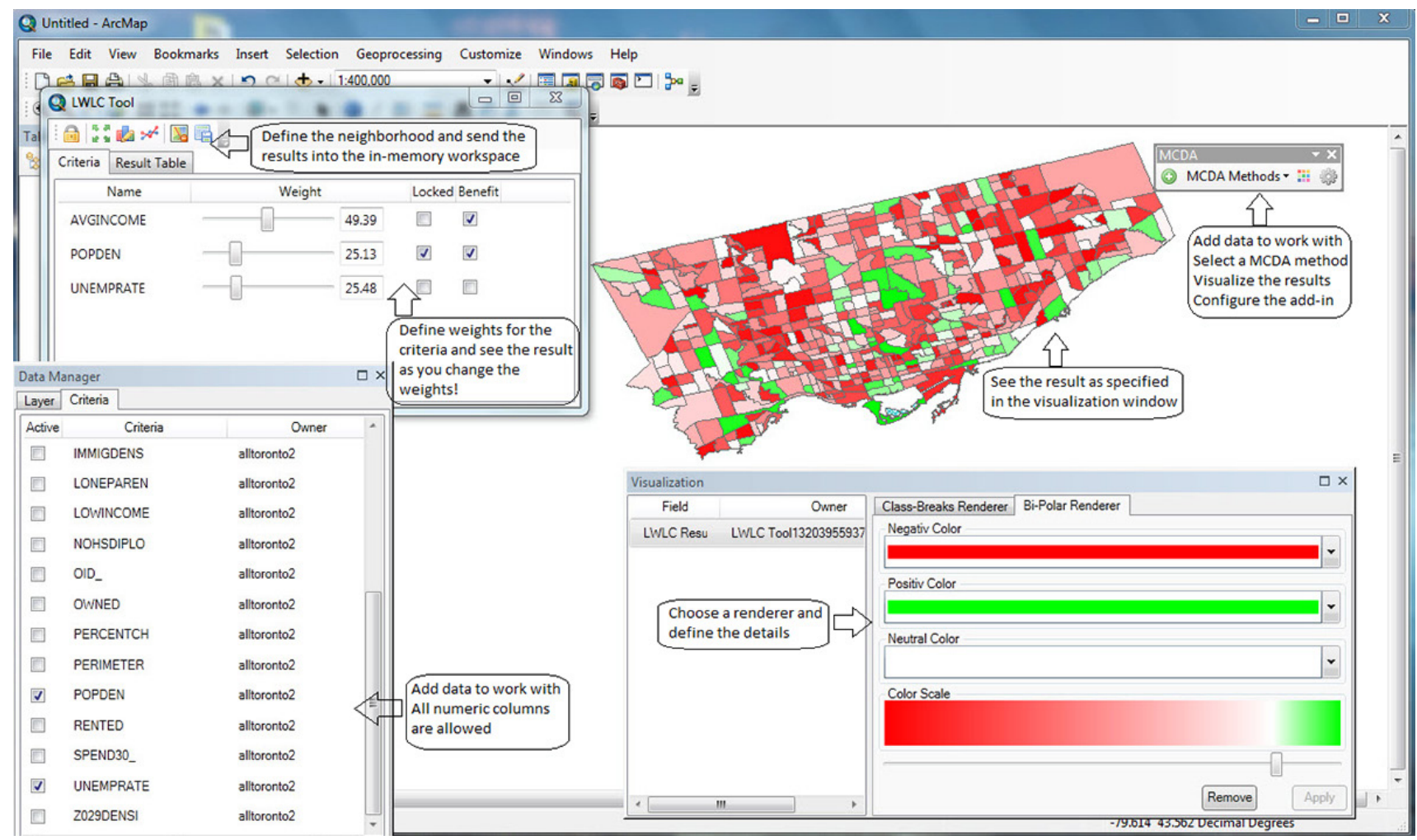

location-specific information), and may be most useful within an exploratory mapping environment.

MCDA4ArcMap is an ArcGIS add-in released as free software under the Apache License 2.0 and available for download at http:// mcda4arcmap.codeplex.com/. It is written in the C\# programming language within the .NET environment, and integrates with the event handling, editing workflows, and data access procedures within ArcGIS. The "Model View ViewModel" architecture pattern separates the program logic from the user interface. Phase I of the development was completed in January 20I3. Anyone in the CCA community is invited to try MCDA4 ArcMap for their own research and practice. If you have ideas for extensions and applications, or encounter issues installing and running it, feel free to contact the authors, or go ahead to improve and use it. As an open-source project, MCDA4ArcMap is only going to be successful if it turns out to be of use to a core group of contributors.

\section{References:}

Andrienko G, Andrienko N, Bernardo F, Hipolito J, Kretschmer $U$, Voss H (2002) Testing the usability of interactive maps in CommonGIS. Cartography and Geographic Information Science, 29, pp. $325-342$

DiBiase D (1990) Visualization in the earth sciences. Earth and Mineral Sciences, Bulletin of the College of Earth and Mineral Sciences, Pennsylvania State University, No. 59, pp. 13-18 Jankowski P, Andrienko N, Andrienko G (200I) Map-centered exploratory approach to multiple criteria spatial decision making. International Journal of Geographical Information Science I5(2): $101-127$

Jiang H, Eastman JR (2000) Application of fuzzy measures in multicriteria evaluation in GIS. International Journal of Geographical Information Systems I4(2): I73-I84

MacEachren AM, Kraak M-J ( 1997) Exploratory Cartographic Visualization: Advancing the Agenda. Computers \& Geosciences 23(4): 335-343

Malczewski J (1999) GIS and multicriteria decision analysis. John Wiley, New York

Malczewski J (20I I) Local Weighted Linear Combination. Transactions in GIS I5(4): 439-455

Rinner C, Taranu JP (2006) Map-Based Exploratory Evaluation of Non-Medical Determinants of Population Health. Transactions in GIS I0(4): 633-649

Rinner C (2007) A Geographic Visualization Approach to MultiCriteria Evaluation of Urban Quality of Life. International Journal of Geographical Information Science 21 (8): 907-919

Slocum T, McMaster RB, Kessler FC, Howard HH (2009) Thematic Cartography and Geovisualization. 3rd edition, Prentice Hall, Upper Saddle River, NJ

'Department of Geography, Ryerson University, 350 Victoria Street, Toronto, Ontario, M5B 2K3 Canada - crinner@ryerson.ca

Institute for Geoinformatics, University of Münster, Weseler Straße 253, 48I5I Münster, Germany - steffan.voss@uni-muenster.de 